\title{
Off the Bench: A Qualitative Investigation into the Experiences of Helpers Working with Edmonton's Street-Involved Youth Population
}

\author{
Kailee Forchuk, Bethany Warkentin, Kim Marshall, Madison Paonessa \\ BCYC, MacEwan University, Alberta, Canada \\ Gerard Bellefeuille, Professor, Department of Child and Youth Care MacEwan University, Alberta, Canada
}

\begin{abstract}
This course-based research study examined the lived experiences of four youth shelter workers. Thepurpose of the qualitative study, which used arts-based data collection methods, was to explore the attitudes, values, and approaches to practice that underpin effective youth shelter work with street-involved youth. A thematic analysis of the data revealed four themes: authenticity, persistence, the ability to overcome challenges, and selfless investment.
\end{abstract}

Keywords: street-involved youth,transient, youth shelters, youth care worker

\section{INTRODUCTION}

The number of street-involved youth in Edmonton, Alberta, is on the rise. In 2014, the Edmonton Social Planning Council (Gill, 2014, p. 10) reported that "the number of homeless children and youth counted in Edmonton had almost doubled from the number counted two years earlier, rising from 123 to 223." Even though each street-involved youth has a different story, the literature suggests that up to 70 percent of youth are on the street because they seek to escape some form of sexual, physical, or emotional abuse by their caregivers (Mallet, Rosenthal, \& Keys, 2005; O'Grady \&Gaetz, 2004). Other related causes include drug use, mental health issues, poverty, and school failure (Gaetz, Donaldson, Richter, \& Gulliver,2013).In addition, a 3-year study launched in 2006 that examined homeless youth in Calgary, Toronto, and St. Johns concluded that a very large number of street-involved youth - approximately 68 percent - have a history of foster care, group home, or a youth centre involvement (Raising the Roof, 2009). Regardless of the personal background or circumstances of this cohort, research suggests that the needs of these youth are complex, particularly because they are prone to many additional social and health consequences as a condition of their street involvement. For example street-involved youth have an increased risk of substance abuse, blood-borne infection, and violence at the hands of and exploitation by adults and peers (Boivin, Roy, Haley, \&Galbaud du Fort, 2005; Krüsi, Fast, Small, Wood, \& Kerr, 2010).Street-involved youth also suffer a mortality rate nearly 11 times higher than the general population of the same age (Boivin et al., 2005).

Not surprisingly, street-involved youth present many challenges to the child and family services system of care. Particularly, their personal histories of neglect and abuse, and the complex needs they manifest as a direct consequence of surviving on the streets, often make it difficult for them to trust youth service providers and to form meaningful relationships with outreach workers, group home staff, or counsellors. As a result, they are often quickly written-off and discharged from their foster home or residential care placements in response to a variety of behavioural issues such as refusal to follow rules, involvement in illicit drug use, refusal to attend school, anda host of other mental health self-harm behaviours.

\section{Youth Shelters}

Youth shelters provide safety and basic needs to street-involved youth and are regarded as the only option for youth hardened by the experience of fending for themselves on the streets. In a 2011 interview with the CBC, Alberta's minister of human services, David Handcock, responded to a CBC investigation into the growing number of youth in homeless shelters by stating, "if a youth is coming out of a chaotic situation, they may not be ready for the rules in a group home" (CBC News, 2011).As the minister's comment reflects, youth shelters are not a straightforward meanstoaddress the issues street-involved youth confront; they do, however, provide a critical access point through whichvulnerable youth can begin to receive the support they desperately require to live more stable lives. 
Youth shelters are specifically designed to support street-involved youth whofind it difficult to trust authority figures and who have a heightened fear of being reported to police or child welfare services because of their current lifestyle. Establishing rapport and a trusting relationship with street-involved youth is therefore of the utmost importancefor CYC workers. Building the trust of street-involved youth, however, is challenging work. The aim of this course-based research study is to gain an increased understanding of what effective youthshelter work. What does it look like and what are the core competencies required of youthshelter staff?

\section{Undergraduate Course-Based Research: A Pedagogical Tool to Foster Criticality, Reflectivity, and Praxis}

The Bachelor of Child and Youth Care program at MacEwan University is continuouslysearches for new pedagogical approaches to foster criticality, reflectivity, and praxis as integral components of the overall student educational experience. As such, the design and implementation of a course-based approach, in contrast to the traditional didactic approach to research-methods instruction, offers fourth-year undergraduate students the opportunity to master introductory research skills by conceptualizing, designing, administering, and showcasing small minimum-risk research projects under the guidance and supervision of the course instructorcommonly, a professor with an extensive background in research and teaching.

Use of course-based researchin higher educationhas soared in recentyears (Allyn, 2013; Bellefeuille,Ekdahl, Kent, \&Kluczny, 2014; Harrison, Dunbar, Ratmansky, Boyd, \&Lopatto, 2011).The benefits derived from a course-based approach to teaching research methods for Child and Youth Care (CYC) students are significant. First, there is value in providing students with authentic learning experiences that enhance the transfer of knowledge obtained in formal education to practice.Past students have reported that their engagement in course-based research has enabled them to expand their depth of scientificknowledge by adopting new methods of creative inquiry.Second, course-based research offers students the opportunityto work with instructors in a relationship characterized by mentoring, which results in a greater number of students who express interest in advancing to graduate studies. Third, the results of course-based research can sometimes be published in peer-reviewed journals and online open-access portals, and thus contributes to the discipline's knowledge base.

Ethical approval required to enable students to conduct course-based research projects was granted to the course instructor by the university's research ethics board (REB). Student research groups are then required to complete an REB application form for each course-based research project undertaken in the class, which is then reviewed by the course instructor and a sub-REB committee to ensure each course-based research project is completed and in compliance with the ethics review requirements of the university.

\section{RESEARCH DESIGN}

For the purpose of this study, we chose an approach that would shine a light on the positive reasons that workers choose to work, and excel at, working, with street-involved youth. We also wanted to give voice to the youth. Our hope is that, with our particular research design,practitioners in the CYC field willgain a broader perspective regardingthe youth involved inthese types of programs and that the research will inspire current and future practitioners to work with the youthpopulation and, in the process, generate a feeling of hope in workersthat can impact the lives of street-involved youth. Highlighting the qualities of effectiveworkers also serves to identify the characteristics that may separate the average worker from a great worker. We rooted our study in an interpretive research paradigm by using interviews and anonymous creative journals to generatean authentic understanding of the questions we were posing.

\section{RESEARCH PARADIGM}

The interpretive paradigm guided the methodological design of this course-based study. The ontological position of interpretivism is relativism, which holds the view that reality is subjective and that its perception differs from person to person (Creswell, 2003). The corecontention of the interpretive paradigm is that reality is a social construct and that knowledge is embedded in social relationships and contextualized within one's social and cultural environment. This is congruent with the underlying epistemological assumption of CYC relational practice that knowledge is embedded in social relationships and thoroughly contextualized within one's a social and cultural milieu (Bellefeuille \& Ricks, 2010).

\section{PURPOSE OF STUDY}

Ourcourse-based study utilized a qualitative approach to determine the lived-experiences of youth workers who support street-involved youthatdifferent levels of programming. The goal was to identify and assesspreciselywhat, makes effective street-involved youth workers as effective as they are. We sought to isolate the characteristics that make workers who engage with this specific population unique. For the purpose of this study, "street-involved youth" was defined as an individual 15-24 years of age who accessed programming specific to "street-involved" or "transient" youth. We did not exclude youth who often find themselves in 
between housing or programs,nor did we exclude youth who youth who lacked stable housing by choice or due to other circumstances (e.g., a youth evicted fromtheir home or onefleeing abuse).

\section{RESEARCH QUESTIONS}

The research aimed to explore the qualities, abilities, and understanding that staff employedwhen working with street-involved youth. The study was established with the following questions in mind:

1. How do staff perceive street-involved youth?

2. How do staff approach their work with this population?

3. How do staff understand the needs of street-involved youth?

4. What motivates staff to work with this population?

\section{SAMPLE POPULATION}

A non-probability, purposive sampling strategy was used to select participants for the study. A total of four staff, two each from two separate youth shelters, formed the sample for the study. Each participanthad worked for a minimum of six months with street-involved youthbetween the ages of 15 and 25 . Themission statements of both sheltersfocused on strength-based practice and the empowerment of youth.

\section{DATA COLLECTION}

Data was collected through the use of creative journaling. Our hope was that participants would be best able to express their thoughts and attitudes toward their everyday work with street-involved youth if they were not limited by a particular medium.Expressivemediums could include writing, drawing, painting, doodling, mindmaps, photographs, and collages.Each journal was marked with a uniqueletter to ensure the confidentiality of the participant.We also created a second research component so that we could include the youth with whomour participants worked. We provided each participant with 5-8 puzzle pieces to distribute to their youth (see image below). We requested that they design a puzzle piece that would articulate toothers something that eachyouth wanted otherstonow or understand about their life. The puzzle pieces were not subject to analysis in our research; nevertheless, eachanonymous piece served to represent a youth's voice by sharing what it was they felt was important for others to know about them.

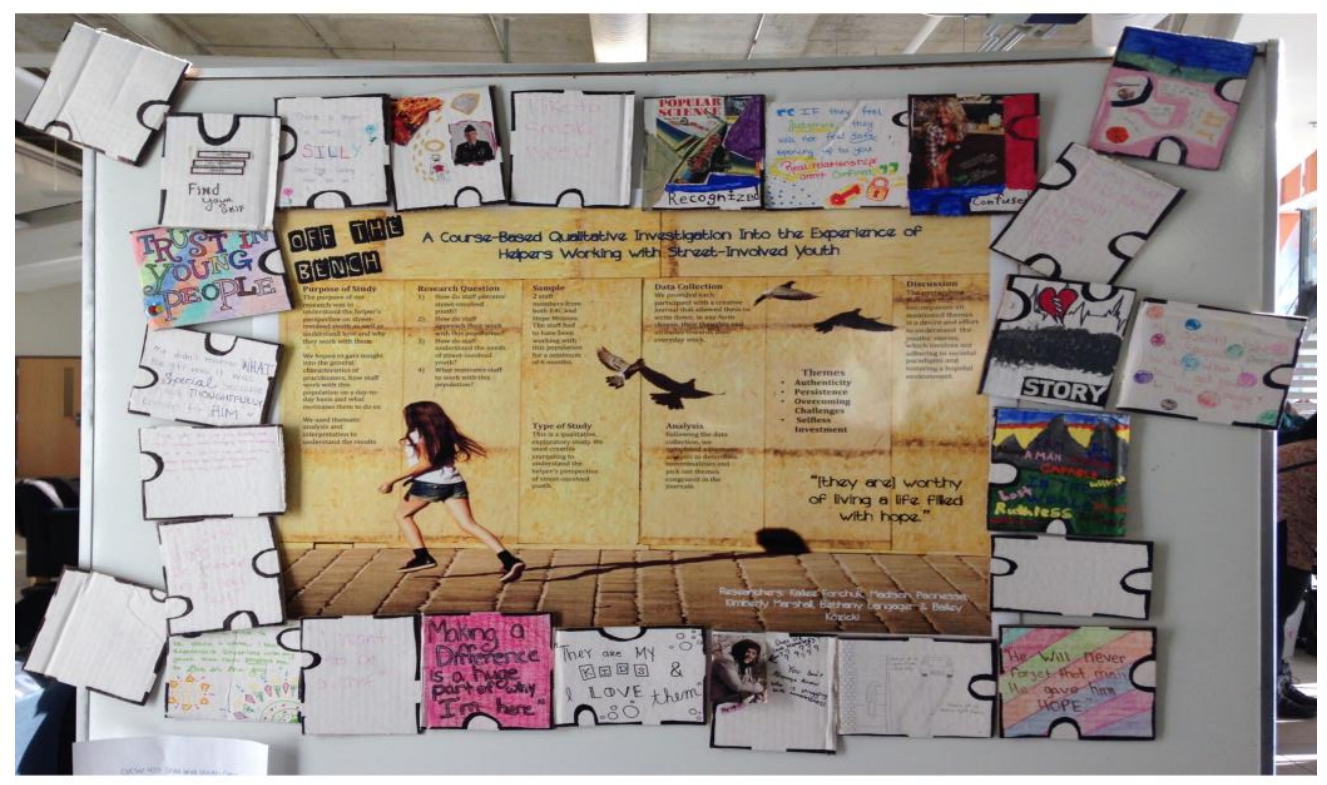




\section{DATA ANALYSIS}

Thematic analysis was usedto analyze data to identifythemesin the youth workers' journals. The thematic analysis method applied in this course-based study is grounded in the essentialist method (Braun \& Clarke, 2006). The essentialist method is an inductive"bottom-up,"anddata-driven approach that examines experiences, meanings, and the reality participants experience. Ontologically, the essentialist approach is predicated on the assumption that realities exist outside the mind (Oderberg, 2007). However, the notion is that while there is a reality out there, it can never fully be realized (Howitt \& Cramer, 2008). The sequence of analysis consists of the six processes that are suggested by Braun and Clarke: (1) familiarizing oneself with the data, (2) generating initial codes, (3) searching for themes, (4) reviewing and refining themes, (5) defining and naming themes, and (6) producing areport.

\section{RESULTS}

Following analysis, four themes emerged that showcased the characteristics of staff whoworked effectively with street-involved youth. These themes include authenticity, persistence, the ability to overcome challenges, and selfless investment.

\section{Authenticity: "I Can Tell You'renot Fake"}

"Authenticity" is an umbrella term used to represent a broad range of characteristics that were displayed by each of the research participants. Their acts of compassion, transparency, and their honesty with streetinvolved youth, as well as with themselves, are attributes that fall withinthis category. One participantexpressedthe importance of authenticity when she wrote, "If you're real with them, even in the tough situations, it'll only strengthen your relationship that much more." Another participant described authenticity asthe commitmentof time;she wrote, "The parameters of my job description say between the hours of 9pm to 9am while I'm on shift. Real relationships aren't confined. I try to be as authentic as I can." The following statement reflects that it is by means ofauthentic relationships that workers were able to connect with youth and build a foundation for their work: "I approach every interaction as though it could be my last. I have yet to determine if this is healthy, however, it ends up being a heart issue for me and I really don't want to live with anymore what ifs."

\section{Persistence: "Never Giveup, You Got This"}

One participant wrote the following:

Watching a youth who has never had a history with addiction experience his first high and know that he will be sucked into the lowest low he will ever feel leaves me helpless but it also leaves me feeling determined to love and care for these youth past the poor choices. If they can see at least one outstretched hand waiting for them they will know that it will be it will be there waiting for them when they come up for air.

This quote summarizes the persistence required of CYC practitionerswhowork each day with street-involved youth. Our participants continued to care for their youth despite being called names, sworn at, and threatened. They displayed acceptance of and support for the youth as they navigated hardships. Participants advocated for and empowered their youth, and they remained determined and hopeful. The participants recognized the strengths of their youthcelebrated successes, and recognized their resiliencies rather than their shortfalls. Thisapproach is highlighted in the following two statements: (1)"Although my heart has often been broken and weary, I've continually had the opportunity to celebrate thousands of amazing achievements. I am humbled that I get to share life in community with some of the world's most talented, brave, and caring people"; and (2),"I have almost been assaulted. I have been threatened. I am constantly sworn at and disrespected. At the end of a crazy night I don't leave wanting a new career. Somehow I am able to look past that at the kids and see that there is a lot more good than bad that goes on. That makes it worth it."

\section{The Ability to Overcome Challenges: "My Mistakes Hauntme"}

The participants described a variety of challenges they face on a daily basis: stigma and stereotypes, vulnerability, navigating boundaries, and the challenge of building trust with street-involved youth. Not only did they describe their advocacy of youth, but their belief in themselves and the work they were doing - despite the opinions of others in their life. The participants described an ability to adapt as they learned from each experience:"My mistakes haunt me...I don’t take responsibility for his actions. I just wished I would have taken those extra seconds, asked those questions, and simply listened. Every interaction since then has changed." And, "Today was hard..."

\section{Selfless Investment: "It Ends up Being a Heart Issue"}

One canassume that individuals get jobs in order to collectan income so that they can afford the cost of living. Whilethis objective is undoubtedly a practical one, not one participant mentioned monetary compensation as a 
reason for doing work with street-involved youth. The participants described a love for the youth, a willingness to walk alongside of them at eachyouth's pace, and a desire to make a difference. For example, "He is worthy of living a life filled with hope..." and,"Making a difference is a huge part of why I'm here."

\section{DISCUSSION}

The findings of this course-based research study are important to the field of CYC becauseit highlights "self" and the "space-between." That is, it underscores the importance of being fully presentof operating in a way thatvaluesdiscovery as a way of being, and the capacity to put aside "knowing" and judgments so that one can see and receive the other without preconceived judgments and attitudes. These tools are the cornerstones of effective relational-centred practice (Bellefeuille \& Jamieson, 2012). Ourfindings highlight the importance of the relational-centred skills and capacities that are taught and practiced within the Bachelor of Child and Youth Care program at MacEwan University. All of the participants expressed a genuine interest in the lives of the street-involved youths with whom they worked and in hearing their individual stories. Participants demonstrated motivation and a persistence in theirapproach to practice in a way that demonstrated acceptance of youth regardless of their circumstances orlife choices. While the course-based study was exploratory and based on a very small sample, it provides a glimpseinto the perspectives of youth shelter workers on the needs of streetinvolved youth and what constitutes effective youth care practice in light of their personal experiences. The imperative to engage in practice-based research is central tothe CYC profession if it is to deliver effective interventions to vulnerable children and youth.

\section{REFERENCES}

[1] Allyn, D. A. (2013). Course-based undergraduate research-It can be accomplished! Journal of Physical Education, Recreation \& Dance, 84(9), 32-36.

[2] Bellefeuille, G., Ekdahl, C., Kent, L., \&Kluczny, M. (2014). A course-based creative inquiry approach to teaching introductory research methods in Child and Youth Care undergraduate education. International Journal of Teaching and Education, 2(2), 1-9.

[3] Bellefeuille, G., \& Jamieson, D. (2008). Relational centred planning: Turning to potential and possibilities. In G. Bellefeuille \& F. Ricks (Eds.), Standing on the precipice: Inquiry into the creative potential of child and youth care practice (pp.37-72). Edmonton, AB: Grant MacEwan Press.

[4] Bellefeuille, G. \& Ricks, F. (2010). Relational inquiry: A child and youth care approach to research. Children and Youth Services Review, 32(10), 1235-1241.

[5] Boivin, J.F., Roy, E., Haley, N., \&Galbaud du Fort, G. (2005). The health of street youth. Canadian Journal of Public Health, 96(6), 432-437.

[6] Braun, V., \&Clarke, V. (2006). Using thematic analysis in psychology. Qualitative Research in Psychology, 3(2), 77-101.

[7] CBC News. (2011). Shelters sometimes only option for youth in care: Minister. Retrieved from http://www.cbc.ca/news/canada/edmonton/shelters-sometimes-only-option-for-youth-in-care-minister1.977087

[8] Creswell, J. W. (2003). Research design: Qualitative, quantitative, and mixed methods approaches (2nd ed.). Thousand Oaks, CA: Sage.

[9] Gaetz, S., Donaldson, J., Richter, T. and Gulliver, T. (2013). The State of Homelessness in Canada. Canadian Homelessness Research Network Press.

[10] Gill, A. (2014, Winter ed.). Sheltering homeless youth. Growing Pains, 10-11.

[11] Krüsi, A., Fast, D., Small, W., Wood, E., \&Kerr, T. (2010). Social and structural barriers to housing among street-involved youth who use illicit drugs. Health and Social Care in the Community, 18(3), 282288.

[12] Harrison, M., Dunbar, D., Ratmansky, L., Boyd, K., \&Lopatto, D. (2010). Classroom-based science research at the introductory level: Changes in career choices and attitude. CBE Life Sciences Education, 10(3), 279-286.

[13] Howitt, D., \& Cramer, D. (2008). Introduction to research methods in psychology. Harlow: Pearson.

[14] Mallet, S., Rosenthal, D., \& Keys, D. (2005). Young people, drug use and family conflict: Pathways into homelessness. Journal of Adolescence, 28(@), 185-199.

[15] Odergerg, D.S. (2007). Real Essentialism. London: Routledge.

[16] O'Grady, B., \&Gaetz, S. (2004). Homelessness, gender and subsistence: The case of Toronto street youth. Journal of Youth Studies, 7(4), 397-416.

[17] Raising the Roof (2009). Youth Homelessness in Canada: The Road to Solutions Brief Summary - May 2009. Retrieved from www.raisingtheroof.org 